\title{
A rapid preparation procedure for laser microdissection-mediated harvest of plant tissues for gene expression analysis
}

\author{
Stian Olsen * (1) and Kirsten Krause
}

\begin{abstract}
Background: Gene expression changes that govern essential biological processes can occur at the cell-specific level. To gain insight into such events, laser microdissection is applied to cut out specific cells or tissues from which RNA for gene expression analysis is isolated. However, the preparation of plant tissue sections for laser microdissection and subsequent RNA isolation usually involves fixation and embedding, processes that are often time-consuming and can lower the yield and quality of isolated RNA.

Results: Infection sites of the parasitic plant Cuscuta reflexa growing on its compatible host plant Pelargonium zonale were sectioned using a vibratome and dried on glass slides at $4{ }^{\circ} \mathrm{C}$ before laser microdissection. High quality RNA (RQI > 7) was isolated from $1 \mathrm{~mm}^{2}, 3 \mathrm{~mm}^{2}$ and $6 \mathrm{~mm}^{2}$ total surface areas of laser microdissection-harvested C. reflexa tissue, with the yield of RNA correlating to the amount of collected material (on average $7 \mathrm{ng}$ total RNA $/ \mathrm{mm}^{2}$ ). The expression levels of two parasite genes previously found to be highly expressed during host plant infection were shown to differ individually between specific regions of the infection site. By drying plant sections under low pressure to reduce the dehydration time, the induced expression of two wound-related genes during preparation was avoided.

Conclusions: Plants can be prepared quickly and easily for laser microdissection by direct sectioning of fresh tissue followed by dehydration on glass slides. We show that RNA isolated from material treated in this manner maintains high quality and enables the investigation of differential gene expression at a high morphological resolution.
\end{abstract}

Keywords: Cuscuta reflexa, Gene expression, Laser microdissection, Parasitic plants, qPCR, Vibratome

\section{Background}

Currently, most research on how the dynamic expression of genes allows plants to control their own development and to respond to stimuli, requires the extraction and isolation of RNA prior to the actual gene expression analysis. Plant organs typically consist of multiple cell and tissue types, and there is an increasing awareness that essential gene expression changes occurring in specific cells or tissues can be overlooked when RNA is isolated from entire organs [1-3]. Laser microdissection (LM) combines microscopy and laser beams to isolate specific tissue or cell types from sections of a specimen $[4,5]$. In

\footnotetext{
*Correspondence: stian.olsen@uit.no

Department of Arctic and Marine Biology, Faculty of Biosciences, Fisheries

and Economics, UiT The Arctic University of Norway, Framstredet 39,

9019 Tromsø, Norway
}

plants, the technique has successfully been applied to study tissue- and cell-specific dynamics of a number of different biomolecules including carbohydrates, metabolites and proteins as well as RNA [6-8]. As the latter is prone to degradation by the activity of the almost omnipresent ribonucleases, the usage of LM to harvest material for gene expression analysis requires a fine-tuned balance between maintaining both histological detail and RNA quality. The crucial stage at which the fate of both tissue morphology and RNA integrity is decided, is the initial preparation of tissues prior to the actual LM. Traditionally, such preparations are time-consuming and involve fixation of the specimen followed by embedding in a compound to allow sectioning of thin slices that are subsequently used for LM $[9,10]$. Paraffin sectioning and cryosectioning are two frequently used methods to

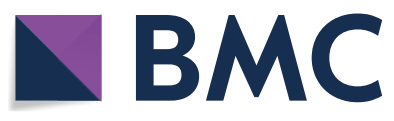

(c) The Author(s) 2019. This article is distributed under the terms of the Creative Commons Attribution 4.0 International License (http://creativecommons.org/licenses/by/4.0/), which permits unrestricted use, distribution, and reproduction in any medium, provided you give appropriate credit to the original author(s) and the source, provide a link to the Creative Commons license, and indicate if changes were made. The Creative Commons Public Domain Dedication waiver (http://creativecommons.org/ publicdomain/zero/1.0/) applies to the data made available in this article, unless otherwise stated. 
prepare sections for LM. In general, RNA isolated from cryosectioned samples has higher quality, whereas paraffin embedding is preferred when the preservation of histological integrity for the identification of specific cell types is essential $[11,12]$. Sample fixation is performed to maintain tissue morphology and to suspend the status of biomolecules during the processes of embedding, sectioning and slide preparation. However, the use of fixatives has been shown to reduce the quality and/or extractability of RNA [13, 14]. Gotte et al. [15] demonstrated that gene expression analysis can be performed on LM-harvested plant material without prior fixation, albeit tissues were not sectioned but directly laser microdissected.

Here, we present a rapid method for preparing plant tissue sections for LM-mediated harvest of material for RNA isolation and apply it to study region-specific gene expression patterns of the infection organ of the parasitic plant Cuscuta reflexa. Parasitic plants steal resources from other plants by developing specialized infection organs called haustoria that invade the tissue of host plants and establish vascular connections between the parasite and its host [16, 17]. LM is an ideal method to unravel molecular changes at the immediate interface where cells from both plants meet [18]. Our method involves vibratome sectioning of freshly harvested infection sites of C. reflexa on its compatible host plant Pelargonium zonale and subsequent dehydration of sections on glass slides. The preparation procedure was evaluated by collecting different amounts of tissue for RNA isolation and comparing RNA yield and quality. Subsequently, the applicability of the method was demonstrated by quantifying the differential expression of the previously identified haustorium-related genes, Cuscuta reflexa xyloglucan endotransglucosylase/hydrolase-1 $(\mathrm{Cr}-\mathrm{XTH}-\mathrm{1})$ and Cuscuta reflexa peroxidase-2 $(\mathrm{Cr}-\mathrm{PX}-2)$ [19], in specific regions of the $C$. reflexa infection organ. To address the inevitable induction of stress gene expression when sectioning live plant material, the expression levels of two wound-related genes were quantified under different sample treatments.

\section{Results}

It is generally declared that protocols for preparing plant tissues for LM need to be optimized on a case-specific basis $[9,11]$. Although this is true, some general factors that influence the yield and quality of RNA isolated from laser microdissected tissue have been identified [10, 12, 20]. These were considered when we developed the method for $C$. reflexa tissues. The stepwise preparation of C. reflexa/P. zonale infection sites for laser microdissection is presented in Fig. 1 and explained in detail in the Methods section. Freshly harvested infection sites were placed in a specimen holder and cut in $100 \mu \mathrm{m}$ thick cross-sections using a vibratome (Fig. 1a, b). Takahashi et al. [20] reported that lowering the temperature at which sections are dehydrated from 42 to $4{ }^{\circ} \mathrm{C}$, improved the integrity of isolated RNA. The same study also showed that the inclusion of an RNase inhibitor when preparing sections on slides, limited RNA degradation during longer incubation times. Accordingly, cut sections were immediately collected and kept in ice-cold water supplemented with an RNase inhibitor, before being transferred to baked non-coated glass slides and dried in a desiccator at $4{ }^{\circ} \mathrm{C}$ (Fig. 1c-f). Dryness was assessed visually and is discernible by the fact that the soft cell layers compress during dehydration, causing the section to be much thinner than the original $100 \mu \mathrm{m}$ (Additional file 1). This procedure was sufficient to adhere the dehydrated sections to the glass slides, allowing several slides with sections ready for laser microdissection to be produced within half a working day (Fig. 1g).

\section{Yield and quality of RNA isolated from LM-collected plant material}

In order to check if this rapid preparation of plant tissues for LM was suitable for downstream gene expression analysis, RNA was isolated from three different quantities $\left(1 \mathrm{~mm}^{2}, 3 \mathrm{~mm}^{2}\right.$ and $6 \mathrm{~mm}^{2}$ total surface areas) of C. reflexa tissue harvested by LM from cross-sections of C. reflexa/P. zonale infection sites (Fig. 2a). Several commercial kits have been developed specifically to facilitate the isolation of RNA from small amounts of biological material. Here, we employed the RNeasy Micro Kit (QIAGEN), which has been used previously to isolate RNA from LM-harvested plant material $[15,21,22]$. To address the success of RNA retrieval from LM-collected $C$. reflexa tissue, the quality and concentration of total RNA were measured using the Experion Automated Electrophoresis System (Bio-Rad) and the Qubit 2.0 Fluorometer (Life Technologies). The yield of total RNA had a positive linear relationship to the amount of tissue used for RNA isolation (Fig. 2d), which indicated that the isolated RNA originated from the tissue harvested by LM. RNA of high quality (RNA quality indicator (RQI) $>7$ ) could be isolated from as little as $1 \mathrm{~mm}^{2}$ C. reflexa tissue. However, the chance of acquiring high quality RNA was generally higher when more material was used for the RNA isolation (Fig. 2). Different storage times of slides with sections in the desiccator at $4{ }^{\circ} \mathrm{C}$ prior to $\mathrm{LM}$ were also tested, ranging from $2 \mathrm{~h}$ to 2 months. Even though RNA of high quality could be isolated from 2 months old sections, the only $6 \mathrm{~mm}^{2}$-sample that did not yield high quality RNA, was collected from sections that had been stored for 2 months before LM. Therefore, we propose that sections prepared on slides as described above are stored in a desiccator at $4{ }^{\circ} \mathrm{C}$ for no longer than 

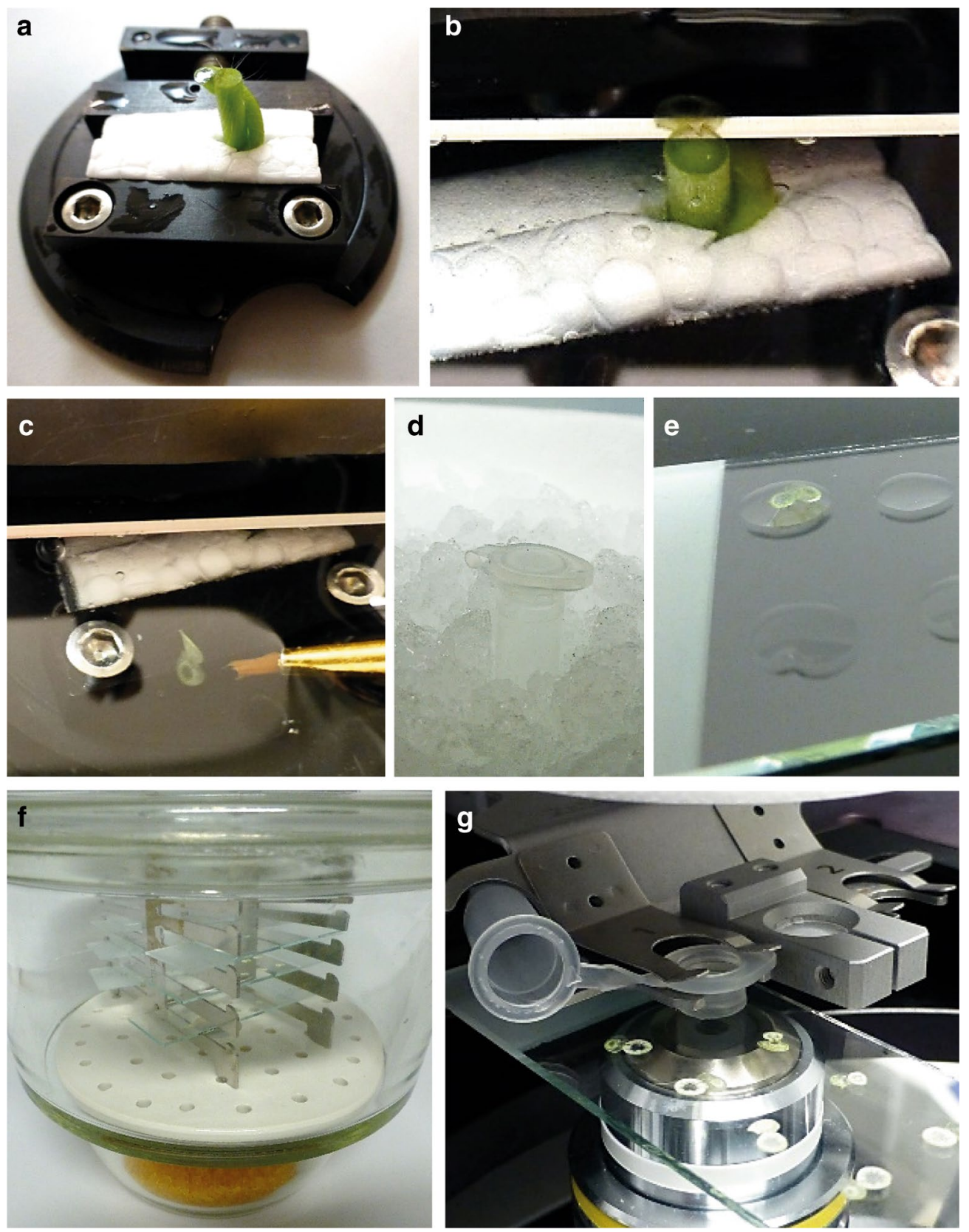

Fig. 1 Preparation of C. reflexa/P. zonale infection sites for laser microdissection. a Infection sites were positioned upright in a specimen holder and $\mathbf{b} 100 \mu \mathrm{m}$ cross-sections produced using a vibratome. c Cut sections were collected immediately and $\mathbf{d}$ stored on ice in tubes with water supplemented with RiboLock RNase Inhibitor before being e transferred to glass slides. After removal of excess liquid using a pipette, $\mathbf{f}$ slides with sections were dried in a desiccator at $4^{\circ} \mathrm{C}$ before harvesting specific tissue regions by $\mathbf{g}$ laser microdissection

1 month before performing LM-mediated harvest of desired regions. For all samples, the duration of storage in a desiccator at $4{ }^{\circ} \mathrm{C}$ prior to LM as well as RNA quantity and quality can be found in Additional file 2 .

As mentioned, sample fixation generally stands in conflict with RNA isolation [13, 14]. However, precipitating fixatives (e.g. alcohols and acetone) do less harm to biomolecules than cross-linking fixatives [14, 23], and are commonly being used when RNA is to be isolated from laser microdissected samples. In order to test the effects of sample fixation on RNA yield and quality, $6 \mathrm{~mm}^{2}$ of $C$. reflexa tissue were also harvested from sections that had been fixed overnight in acetone, which has been reported to be a suitable fixative for preserving RNA through 
a
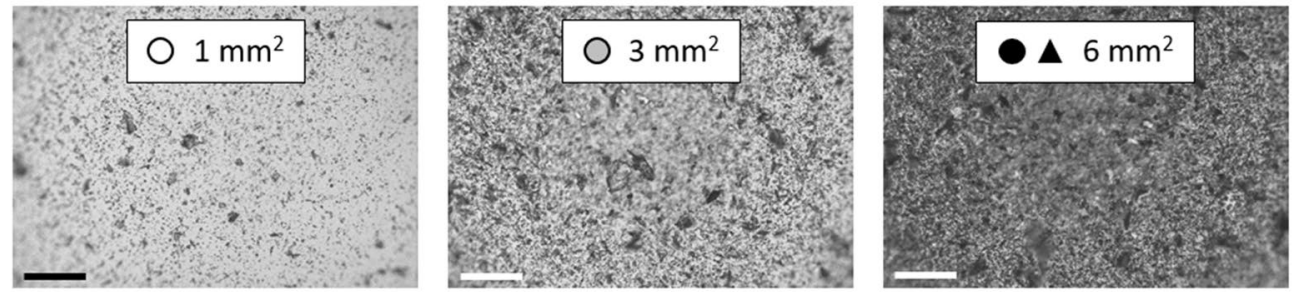

b

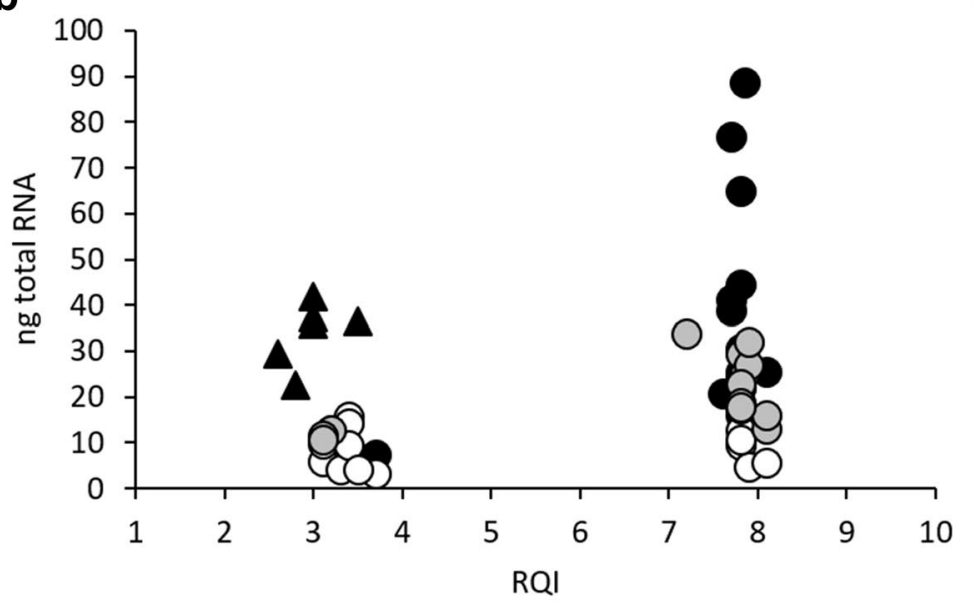

C

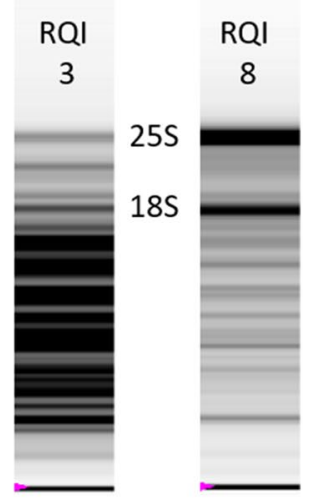

d

\begin{tabular}{r|rrrr} 
& $01 \mathrm{~mm}^{2}$ & $03 \mathrm{~mm}^{2}$ & $\mathbf{1} \mathrm{mm}^{2}$ & $\boldsymbol{\Delta}$ Acetone-fixed \\
\hline n total samples & 14 & 15 & 15 & 6 \\
n samples with RQI > 7 & 5 & 12 & 14 & 0 \\
Average ng total RNA \pm SD & $8.8 \pm 4.1$ & $21 \pm 7.5$ & $37 \pm 23$ & $34 \pm 6.9$
\end{tabular}

Fig. 2 Effects of tissue quantity harvested by LM on RNA yield and integrity. a Surfaces of representative collection tube caps after harvest of $1 \mathrm{~mm}^{2}, 3 \mathrm{~mm}^{2}$ and $6 \mathrm{~mm}^{2}$ total surface areas of C. reflexa tissue (scale bars $=150 \mu \mathrm{m}$ ). b Yields and respective RNA quality indicators (RQIs) of RNA isolated from $1 \mathrm{~mm}^{2}$ (white circles), $3 \mathrm{~mm}^{2}$ (grey circles) and $6 \mathrm{~mm}^{2}$ [black circles and triangles (acetone-fixed)] total surface areas. c Example gel pictures displaying $R N A$ isolates with $R Q I=3$ and $R Q I=8$. d Average $R N A$ yields and frequencies of samples showing high $R N A$ quality $(R Q I>7)$

preparations for LM [10, 11, 24]. With our method, the quantitative yield of RNA was comparable between acetone-fixed and non-fixed material (Fig. 2d). However, as overnight acetone fixation appeared to reduce the quality of the isolated RNA, it was not included in the preparation procedure.

\section{Differential gene expression in specific tissue regions of $C$. reflexa during host infection}

Besides the preservation of RNA quality throughout the section preparation and LM-mediated harvest of plant material, it is essential that the isolated RNA is suitable for the identification of gene-specific expression patterns.
To address this, RNA was isolated from about $6 \mathrm{~mm}^{2}$ material collected from four different regions of the $C$. reflexa/P. zonale infection site (Fig. 3): the parasite region of the cross-section that is furthest away from the host plant (Fig. 3a), the side regions of the parasite containing elongating cells (Fig. 3b) as well as the inner and outer regions of the haustorium inside the host plant (Fig. 3c). Three biological replicates were collected and each replicate contained material of the respective $C$. reflexa region harvested from around 30 sections that originated from at least five different haustoria. After measuring the concentrations and qualities of RNA isolates, amplified 

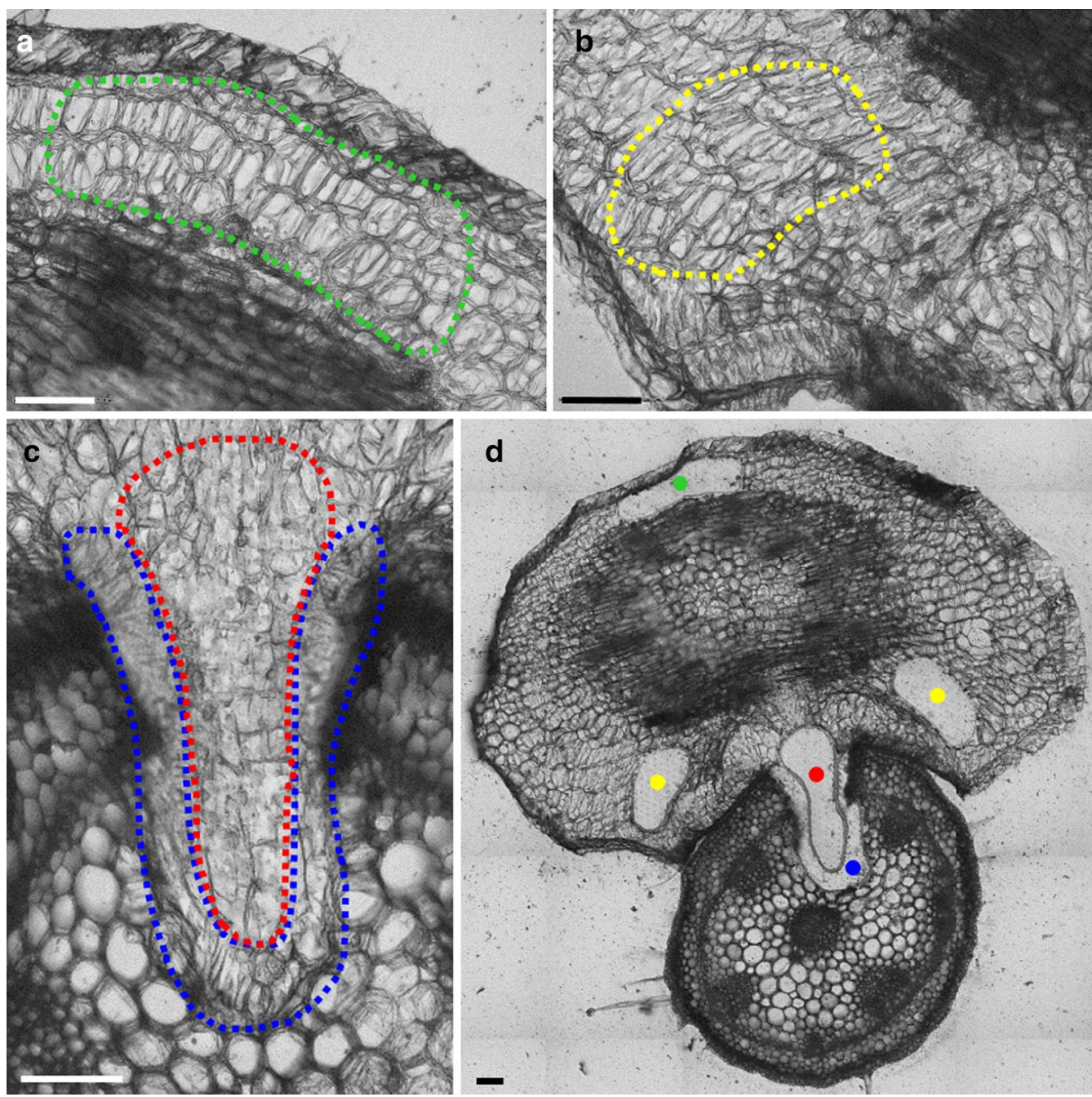

Fig. 3 Regions of the C. reflexa/P. zonale infection site harvested by LM for gene expression analysis. a The parasite region of the section most distal to the host (green), $\mathbf{b}$ the swelling side regions of the parasite with elongating cells (yellow) and $\mathbf{c}$ the inner body of the haustorium (red) as well as the haustorium interface closest to $P$. zonale (blue). $\mathbf{d}$ The entire cross-section after laser microdissection. All scale bars $=150 \mu \mathrm{m}$

cDNA was generated from 10 ng total RNA (RQI > 7) using the Ovation RNA-Seq System V2 (NuGEN).

In a previous study, we identified two cell wall-related genes, $C r-P X-2$ and $C r-X T H-1$, which were highly expressed in young haustoria of C. reflexa [19]. Displaying dynamic expression patterns between larger organs of $C$. reflexa and being most highly expressed in the haustorium, these genes were good candidates to test for expressional differences between specific tissue regions of the infection organ. The expression stabilities of reference genes used to normalize expression levels across a set of samples are crucial for the generation of reliable gene expression data [25]. Thus, in addition to $C r-P X-2$ and $\mathrm{Cr}-\mathrm{XTH}-\mathrm{1}$, the relative transcript quantities of five potential reference genes [Cuscuta reflexa ubiquitinconjugating enzyme 28 (Cr-UBC28), Cuscuta reflexa tubulin alpha-2 chain (Cr-TUA2), Cuscuta reflexa glyceraldehyde-3-phosphate dehydrogenase $\mathrm{C} 2$ (Cr-GAPC2), Cuscuta reflexa glucose-6-phosphate dehydrogenase 6 (Cr-G6PD6) and Cuscuta reflexa elongation factor 1 alpha $(C r-E F 1 a)]$ were measured in the four different regions of the cross-section by performing quantitative real-time polymerase chain reaction ( $\mathrm{qPCR}$ ) on the amplified cDNA. The total span of quantification cycle (Cq) values across all samples were much smaller for the candidate reference genes than for the haustoriumrelated genes, $\mathrm{Cr}-\mathrm{PX}-2$ and $\mathrm{Cr}-\mathrm{XTH}-1$ (Additional file 3). This was expected as the candidate reference genes were selected based on earlier reports showing relatively stable expression of similarly annotated genes in other plant species [26-28]. To more precisely compare the expression stabilities of the five candidate reference genes, the 


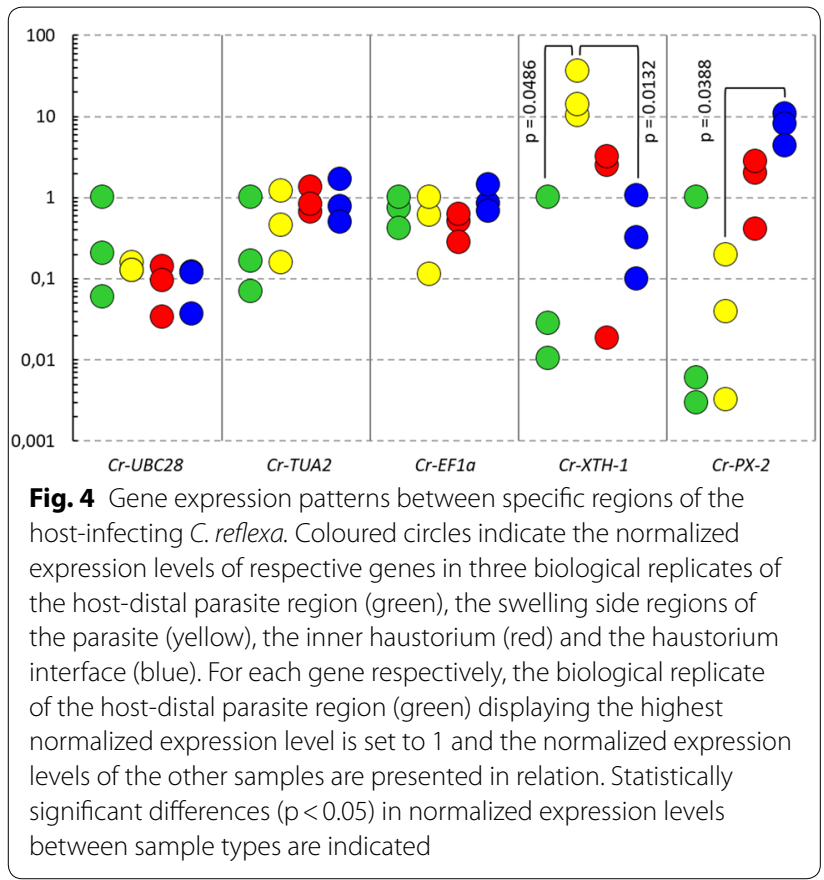

NormFinder algorithm was used to calculate the stability value [29], and the coefficient of variation $\mathrm{CV}$ and the stability parameter $\mathrm{M}$ were calculated as described by Hellemans et al. [30]. Based on the calculated values (Additional file 4), Cr-GAPC2 and Cr-G6PD6 were chosen as the most suitable reference genes for the current sample set and normalized expression levels were calculated using the mean relative quantities of these two genes. When normalized to $C r-G A P C 2$ and $C r-G 6 P D 6$, the expression levels of the three remaining candidate reference genes $(\mathrm{Cr}-U \mathrm{UC} 28, \mathrm{Cr}-\mathrm{TUA2}$ and $\mathrm{Cr}-\mathrm{EF1a})$ were more or less stable across the sample range (Fig. 4), with no differences between the tissue regions found to be statistically significant $(\mathrm{p}<0.05)$. On the contrary, the normalized expression levels of the two cell wallrelated genes, $\mathrm{Cr}-\mathrm{XTH}-\mathrm{1}$ and $\mathrm{Cr}-\mathrm{PX}-2$, varied much more between the investigated regions (Fig. 4). The expression of $\mathrm{Cr}$-XTH-1 was clearly highest in the swelling side regions of $C$. reflexa and were found to be significantly higher than the levels of $\mathrm{Cr}$-XTH-1-expression in the host-distal parasite region or at the haustorium interface. The highest expression level of $\mathrm{Cr}-\mathrm{PX}-2$ was detected at the haustorium interface and differed significantly from the expression in the swelling side regions of the parasite.

\section{Assessment and prevention of stress responses triggered by the preparation procedure}

The sectioning of fresh plant material followed by slow dehydration at $4{ }^{\circ} \mathrm{C}$ is prone to induce gene expression regulations in response to wounding, drought or cold stresses [31]. In tomato, the transcript abundances of the

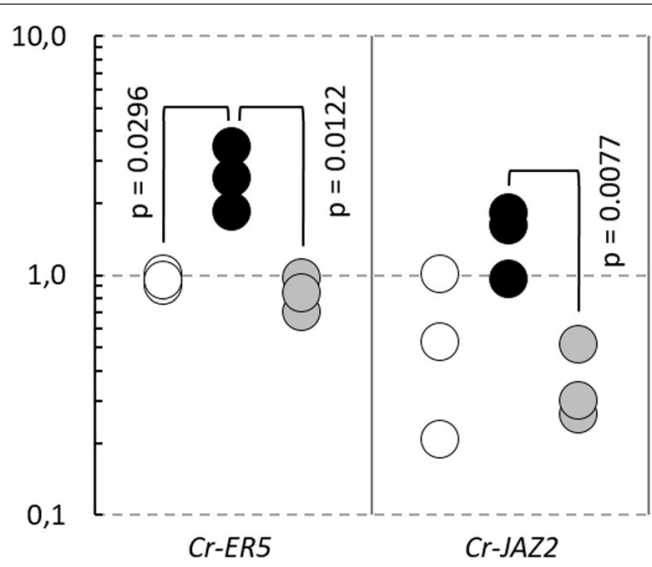

Fig. 5 Expression of wound-related genes in differently treated $C$. reflexa tissue. Circles indicate the normalized expression levels of $C r$-ER5 and Cr-JAZ2 in three biological replicates of C. reflexa material snap-frozen in liquid nitrogen (white), vibratome-sectioned $C$. reflexa material dried in a desiccator at $4{ }^{\circ} \mathrm{C}$ for at least $2 \mathrm{~h}$ (black) and vibratome-sectioned C. reflexa material dried under low pressure at $4{ }^{\circ} \mathrm{C}$ for $15 \mathrm{~min}$ (grey). For each gene respectively, the biological replicate of the snap-frozen C. reflexa material (white) displaying the highest normalized expression level is set to 1 and the normalized expression levels of the other samples are presented in relation. Statistically significant differences $(p<0.05)$ in normalized expression levels between sample types are indicated

ethylene-responsive late embryogenesis-like protein 5 (ER5, Solyc01g095140) and the jasmonate ZIM-domain protein 2 (JAZ2, Solyc12g009220) have been reported to increase rapidly in response to wounding [32,33]. The expression of $E R 5$ is also induced by drought [34]. To test if the LM preparation procedure described above triggers such stress responses, the expression levels of $C r-E R 5$ and Cr-JAZ2 (closest C. reflexa homologues to Solyc01g095140 or Solyc12g009220, respectively) were measured in parasite tissue that had been either snap-frozen in liquid nitrogen or vibratome-sectioned and dried in a desiccator at $4{ }^{\circ} \mathrm{C}$ for at least $2 \mathrm{~h}$. The results show that the expression levels of both wound-related genes were higher in the vibratomesectioned and slowly dehydrated C. reflexa material (Fig. 5), indicating an unwanted alteration of expression profiles. A considerable acceleration of the dehydration process was achieved by performing it under low pressure $(-0.9$ bar $)$ on a $4{ }^{\circ} \mathrm{C}$ cold metal block, shortening the required dehydration time from $2 \mathrm{~h}$ to $15 \mathrm{~min}$. Quick drying did not influence the adhesion of the sections to the glass slides, but prevented the induction of $\mathrm{Cr}$-ER5 and $\mathrm{Cr}-J A Z 2$ in the vibratome-sectioned parasite tissue (Fig. 5).

\section{Discussion}

Laser microdissection enables the isolation of specific cell or tissue types for further downstream analysis, allowing researchers to study biological processes at a 
high morphological resolution. The preparatory steps up to the LM-mediated harvest of the desired tissue regions greatly affect the outcome of downstream analyses. With regards to performing gene expression analysis on RNA isolated from LM-collected material, both the quantity and the quality of the isolated RNA are of importance. Applying the method presented here, plant material can be rapidly processed from initial sample harvest to sections ready for LM. Based on the isolation of RNA from $1 \mathrm{~mm}^{2}, 3 \mathrm{~mm}^{2}$ and $6 \mathrm{~mm}^{2}$ total surface areas of C. reflexa (Fig. 2), the average yield per $\mathrm{mm}^{2}$ tissue is $7 \mathrm{ng}$ total RNA. Measurements of C. reflexa cell sizes in the sections used for LM-mediated harvest indicated that the average surface area of collected cells is $3864 \mu \mathrm{m}^{2}$ (data not shown), which means that the average yield of total RNA per C. reflexa cell area is $27 \mathrm{pg}$. However, as observed by the overlapping cell walls in Fig. $3 a$, b, the $100 \mu \mathrm{m}$ thick sections contain more than one cell layer in depth. Estimating that the sections encompass on average two cell layers, the average yield would be $13.5 \mathrm{pg}$ total RNA per C. reflexa cell. This is comparable to yields reported by others isolating RNA from plant material harvested by LM $[9,24]$. When harvesting material from sections that are more than one cell layer thick, the homogeneity of the microdissected material may become an issue. In the presented example, the host-invading $C$. reflexa haustorium has a uniform morphology over a stretch of $0.5-1 \mathrm{~mm}$ on the longitudinal axis (Additional file 5), preventing the risk of contamination with tissue types other than the ones targeted. Vibratome-produced plant tissue sections of only $20-60 \mu \mathrm{m}$ thickness have been reported [35-38], demonstrating the possibility of applying this preparation procedure for less homogenous structures. Still, the section thickness does constitute a limitation of the presented method for use in single-cell studies.

When the laser microdissected tissue is catapulted into the adhesive cap using the AutoLPC function of the PALM MicroBeam, the collected plant material is fragmented (Fig. 2a). As the degree of tissue fragmentation is not uniform, the observed variations in RNA yield from $6 \mathrm{~mm}^{2}$ harvested C. reflexa tissue could be explained by variations in the fragment sizes of the collected material, since RNA would be extracted less efficiently from larger tissue fragments. It has also been suggested that if catapulted pieces hit areas of the adhesive cap that are already covered by LM-harvested material, they could fail to stick [21]. Even the lowest amount of total RNA isolated from harvested C. reflexa tissue ( $3 \mathrm{ng}$ from $1 \mathrm{~mm}^{2}$, Additional file 2) would be sufficient to produce amplified cDNA using the Ovation RNA-Seq System V2 (NuGEN). As such, the described method could be applied to do gene expression analysis on much smaller amounts of
LM-harvested material than the $6 \mathrm{~mm}^{2}$ used here. However, we observed that the probability of obtaining high quality RNA increased with the amount of collected tissue and that, when collecting $6 \mathrm{~mm}^{2}$, the RNA quality indicator ranged between 7.6 and 8.2 (Additional file 2). This level of RNA intactness is comparable to the highest reported integrity values for RNA isolated from LMharvested material prepared using precipitative fixatives or by direct freezing $[10,18,20,39]$.

Among the four investigated regions of the crosssectioned $C$. reflexa/P. zonale infection sites, the highest expression levels of $\mathrm{Cr}-\mathrm{XTH}-1$ were found in the three biological replicates of the swelling side regions of the parasite. Likewise, all three biological replicates supported that the expression of $C r-P X-2$ was highest at the haustorium interface. In addition to the coinciding expression levels between biological replicates, the observed gene expression patterns make sense in light of the predicted functions of the respective gene products. $\mathrm{Cr}-\mathrm{XTH}-1$ encodes a cell wall-modifying enzyme, the activity of which has previously been connected to plant growth in general as well as haustorium development and host plant infection in Cuscuta $[19,40,41]$. The high expression of $\mathrm{Cr}$ - $\mathrm{XTH}-1$ in the host-enveloping side regions of $C$. reflexa indicate that this enzyme could be specifically involved in the rapid elongation of cells that is occurring in this region (Figs. 3b, 4). High activity of plant peroxidases has been associated with Cuscuta host infection $[42,43]$. The fact that the peroxidase-encoding $C r-P X-2$ gene is most highly expressed at the haustorium interface (Figs. 3c, 4), suggests that this gene product could be directly involved in plant tissue penetration or in quenching host plant defense responses. Thus, gene expression patterns identified using the presented method can provide valuable biological insight, at a high morphological resolution. When testing if stress responses were triggered by the preparation procedure, it was found that the expression levels of the wound-related genes $\mathrm{Cr}$-ER5 and $\mathrm{Cr}$-JAZ2 were higher in C. reflexa material dehydrated in a desiccator at $4{ }^{\circ} \mathrm{C}$ for $2 \mathrm{~h}$ than in snap-frozen material (Fig. 5). By performing the drying at $4{ }^{\circ} \mathrm{C}$ under low pressure, the required dehydration time was shortened to $15 \mathrm{~min}$. This prevented the increased expression of both wound-related genes, implying that changes in expression levels-at least of the genes here tested-do not occur instantly. All the same, as wounding alone has been reported to induce the expression of $\sim 1000$ tomato genes just $30 \mathrm{~min}$ after treatment [33], a complete avoidance of stress gene responses cannot be expected during the processes of sectioning and drying live plant material. Still, such responses were shown to be reducible while maintaining the preparation time prior to $\mathrm{LM}$ at a minimum. 


\section{Conclusions}

We present a rapid procedure for the preparation of plant tissues sections for laser microdissection-mediated harvest of specific tissue regions. The method avoids fixation and embedding of plant material and utilizes a vibratome to make fresh tissue sections that are transferred to glass slides and dried at $4{ }^{\circ} \mathrm{C}$. The short processing time allows initial sample harvest, sectioning and dehydration as well as laser microdissection, all to be carried out on the same day. RNA of high quality and sufficient quantity for gene expression analysis could be isolated from the LM-harvested material. We demonstrated the applicability of the method by identifying gene-specific expression levels in different tissue regions of the parasitic plant $C$. reflexa during infection of a host plant. Dehydration of tissue sections under low pressure reduced the drying time and prevented the induction of two stress genes.

\section{Methods}

\section{Growth and harvest of plant material}

Cuscuta reflexa was propagated on Pelargonium zonale under continuous light at $21{ }^{\circ} \mathrm{C}$ in a greenhouse at the Climate Laboratory of UiT The Arctic University of Norway (Holt, Tromsø). P. zonale petioles infected with C. reflexa at the penetrating stage of haustorium development (identified as described by Olsen et al. [19]) were detached from the main plant and used for sectioning.

\section{Sectioning and slide preparation}

Freshly harvested $C$. reflexa/P. zonale infection sites were sectioned using a Leica VT1000 E vibrating blade microtome (vibratome). The apical-basal length of infection sites was trimmed to approximately $1.5 \mathrm{~cm}$ and positioned upright in the specimen holder, leaving about $1 \mathrm{~cm}$ of the infection site above the holder and accessible for sectioning. Pieces of polystyrene were placed around the specimen to ease the pressure on the plant tissue when fastening it between the clamping jaws. The specimen holder with an immobilized infection site was placed in a buffer tray that was filled with tap water to fully submerge the specimen. Sections of $100 \mu \mathrm{m}$ thickness were made with the following settings: control knob of knife advancement speed set to 2 and control knob of knife vibration frequency set to 10 . Cut sections were immediately transferred to tubes with distilled water supplemented with $1 \mathrm{U} / \mu$ l RiboLock RNase Inhibitor (Thermo Fisher Scientific) and placed on ice. For trials with acetone fixation, cut sections were instead transferred to tubes with $100 \%$ acetone on ice. The fixative was changed once before incubation overnight at $4{ }^{\circ} \mathrm{C}$. Single sections were transferred to $5 \mu \mathrm{l}$ drops of distilled water supplemented with $1 \mathrm{U} / \mu \mathrm{l}$ RiboLock RNase Inhibitor spotted on baked $\left(\geq 4 \mathrm{~h}\right.$ at $\left.200{ }^{\circ} \mathrm{C}\right)$ glass slides. Excess liquid was removed using a pipette before commencing the dehydration process. The slides with the sections were either dried in a desiccator at $4{ }^{\circ} \mathrm{C}$ for at least $2 \mathrm{~h}$ or dried on a $4{ }^{\circ} \mathrm{C}$ cold metal block in a vacuum chamber (-0.9 bar) for $15 \mathrm{~min}$.

\section{Laser microdissection}

Specific regions of the infecting parasite were harvested from dry sections of $C$. reflexa/P. zonale infection sites on glass slides using the PALM MicroBeam (Zeiss) laser microdissection system with the PALMRobo V4.2 software. The circumferences of regions to be harvested were drawn using the freehand tool. Cutting and laser pressure catapulting (LPC) were done using the CloseCut + AutoLPC function with the following settings: $10 \times$ objective, $30 \%$ cut speed, $70 \%$ cut energy, $90 \%$ cut focus, $47 \%$ LPC speed, $95 \%$ LPC energy and $89 \%$ LPC focus. The selected tissue regions were catapulted into the cap of AdhesiveCap 500 clear tubes (Zeiss) placed in the TubeCollector $2 \times 500 \mathrm{CM}$ II (Zeiss) at a working height of $-15,356$. Images were taken with the AxioCam ICc1 (Zeiss).

\section{RNA isolation, quality control and preparation of amplified CDNA}

RNA isolation was carried out using the RNeasy Micro Kit (QIAGEN). After laser microdissection, $200 \mu \mathrm{l}$ buffer RLT supplemented with $\beta$-mercaptoethanol $(10 \mu \mathrm{l} / \mathrm{ml})$ were added to the tubes with the LM-collected samples and mixed by vortexing for $30 \mathrm{~s}$. Following, the tubes were kept upside down (to ensure contact of the LMcollected material in the cap and the buffer) for $5 \mathrm{~min}$ before vortexing again for $30 \mathrm{~s}$. Tissue lysates were collected by centrifugation at $8000 \times g$ for $1 \mathrm{~min}$ and transferred to new tubes that were directly processed further or stored at $-80{ }^{\circ} \mathrm{C}$. The remaining steps of the RNA isolation were executed following the protocol described for microdissected cryosections in the RNeasy Micro Handbook (third edition (12/2014), QIAGEN), starting from point 5 in the procedure and including on-column DNA digestion. The quantity and quality of isolated RNA were checked using the Qubit 2.0 Fluorometer with the Qubit RNA HS Assay Kit (Life Technologies) and the Experion Automated Electrophoresis System with Experion RNA HighSens Chips (Bio-Rad). The Ovation RNASeq System V2 (NuGEN) was used to generate amplified cDNA from total RNA. The amplified cDNA was purified using Agencourt Beads (Beckmann Coulter) as described in the Ovation RNA-Seq System V2 user guide, after which purity and concentration were measured using the NanoDrop ND-1000 Spectrophotometer (NanoDrop 
Technologies) and the Qubit 2.0 Fluorometer with the Qubit dsDNA HS Assay Kit (Life Technologies).

\section{Quantitative real-time PCR and expression analysis}

Quantitative real-time polymerase chain reaction (qPCR) was set up in technical duplicates of $20 \mu$ reactions containing $1 \times$ SsoFast EvaGreen Supermix (Bio-Rad), $1 \mathrm{ng}$ purified amplified cDNA, $500 \mathrm{nM}$ forward primer and $500 \mathrm{nM}$ reverse primer. The CFX96 Real-Time PCR Detection System (Bio-Rad) was used for amplification and fluorescence detection with the following cycling conditions: $95{ }^{\circ} \mathrm{C}$ for $30 \mathrm{~s}$ followed by 40 cycles of $95{ }^{\circ} \mathrm{C}$ for $5 \mathrm{~s}$ and $61{ }^{\circ} \mathrm{C}$ for $5 \mathrm{~s}$. After 40 cycles, melt curves of amplicons were recorded by stepwise heating from 65 to $95{ }^{\circ} \mathrm{C}$. Data was analysed using the CFX Manager 3.1 software (Bio-Rad). All quantification cycles (Cqs) were determined by setting Single Threshold to 200 relative fluorescence units. The performance of each primer pair-specific qPCR assay was evaluated by generating standard curves using serial dilutions of purified amplified cDNA as template. Only primer pairs amplifying single qPCR products at an efficiency of $90-110 \%$ and with sizes as expected based on a C. reflexa transcriptome [19], were used for gene expression studies. Genespecific primer sequences with respective amplicon sizes and qPCR amplification efficiencies, as well as melt peaks and size separation by agarose gel electrophoresis of respective qPCR amplicons are stated in Additional file 2. As some of the tissue regions of $C$. reflexa that were collected by LM are in close proximity to the host plant $P$. zonale, all qPCR primer pairs were tested on cDNA synthesized from $P$. zonale RNA in order to verify that the primers were specific to the parasite (data not shown). Relative quantities (RQs) of gene transcripts were calculated by the formula $2^{\left(\mathrm{Cq}_{\mathrm{control}}-\mathrm{Cq}_{\mathrm{sample}}\right)}$. In samples where a gene-specific amplicon could not be detected in any of the technical duplicates, a Cq value equal to the highest measured $\mathrm{Cq}$ value of the respective amplicon was assigned. Expression stabilities were evaluated by calculating the coefficient of variation $\mathrm{CV}$ and the stability parameter $\mathrm{M}$ as described by Hellemans et al. [30], and by calculating the stability value using the Excel add-in "NormFinder" with Microsoft Excel 2016 [29]. Normalized expression levels were calculated by dividing the RQ of target gene against the geometric mean of the RQs of $C r-G A P C 2$ and $C r-G 6 P D 6$, for the respective sample. The statistical significance of differences between log-transformed normalized expression levels were calculated using an unpaired two-tailed $t$ test assuming unequal variances. All gene expression data and $\mathrm{p}$-values are stated in Additional file 2.

\section{Additional files}

Additional file 1. Vibratome-sectioned C. reflexa/P. zonale infection site before and after dehydration. a Immediately after cutting, the $100 \mu \mathrm{m}$ thick section was placed on a glass slide that was slightly tilted in order to inspect the thickness of the sections. $\mathbf{b}$ After leaving the section to dry, the soft tissues of parasite ( $p$ ) and host (h) have collapsed. Stereomicroscopy was carried out using the SteREO Lumar.V12 (Zeiss).

Additional file 2. RNA and qPCR data. RNA quantity, quality and duration of storage in a desiccator at $4^{\circ} \mathrm{C}$ prior to LM. Gene expression data including $\mathrm{Cq}$ values, calculations and p-values. Gene-specific primer sequences, expected amplicon sizes and qPCR amplification efficiencies calculated based on standard curves of diluted CDNA. Size separation of qPCR amplicons on a $2 \%$ agarose gel under constant voltage set to 100 (nucleic acids were stained with GelRed and visualized using the ChemiDoc MP Imaging System (Bio-Rad). The GeneRuler 50 bp Ladder (Life Technologies) was included for size estimation). Melt peaks of qPCR amplicons generated by plotting the negative derivative of the change in fluorescence intensity as a function of temperature.

Additional file 3. Span of quantification cycle $(\mathrm{Cq})$ values of $C$. reflexa genes. All Cq values of Cr-UBC28, Cr-TUA2, Cr-GAPC2, Cr-G6PC2, Cr-EF1A $C r-X T H-1$ and $C r-P X-2$ in all 12 samples (4 tissue regions $\times 3$ biological replicates) are included in the plot. Lower, middle and upper box lines represent the 1st quartile, 2nd quartile (median) and 3rd quartile, respectively. Whiskers show highest and lowest $\mathrm{Cq}$ values for the respective gene.

Additional file 4. Ranking of best suitable reference genes based on calculated expression stability values. The coefficient of variation $\mathrm{CV}$ and the stability parameter $\mathrm{M}$ were calculated as described by Hellemans et al. [30]. The stability value was calculated using the NormFinder algorithm [29]. For all three calculated values, lower numbers indicate more stable expression.

Additional file 5. Serial sectioning through a C. reflexa haustorium. Using a vibratome, $100 \mu \mathrm{m}$ thick cross-sections were made in series from the start $(0 \mathrm{~mm})$ to the end $(1.3 \mathrm{~mm})$ of a single haustorium. Stereomicroscopy was carried out using the SteREO Lumar.V12 (Zeiss).

\section{Abbreviations}

Cq: quantification cycle; LM: laser microdissection; LPC: laser pressure catapulting; $\mathrm{GPCR}$ : quantitative real-time polymerase chain reaction; $\mathrm{RQ}$ : relative quantity; RQI: RNA quality indicator.

\section{Acknowledgements}

We thank Leidulf Lund (UiT The Arctic University of Norway) for plant care and maintenance and Anne Grethe Hestnes (UiT The Arctic University of Norway) for microscopy assistance. Julien Hollmann (University Hospital SchleswigHolstein) and Karsten Fischer (UiT The Arctic University of Norway) are thanked for stimulating discussions. The publication charges for this article have been funded by a grant from the publication fund of UiT The Arctic University of Norway.

\section{Authors' contributions}

SO and KK conceived and planned the research. SO performed the experiments. SO and KK analysed and interpreted the data. Both authors participated in the writing of the manuscript. Both authors read and approved the final manuscript.

\section{Funding}

The research presented here was supported by Troms $\varnothing$ Research Foundation toppforsk project 16-TF-KK to K. Krause.

Availability of data and materials

The datasets supporting the conclusions of this article are included within the article and its additional files.

Ethics approval and consent to participate Not applicable. 


\section{Consent for publication}

Not applicable.

\section{Competing interests}

The authors declare that they have no competing interests.

Received: 7 March 2019 Accepted: 26 July 2019

Published online: 02 August 2019

\section{References}

1. Brandt SP. Microgenomics: gene expression analysis at the tissue-specific and single-cell levels. J Exp Bot. 2005;56(412):495-505.

2. Shinozaki Y, Nicolas P, Fernandez-Pozo N, Ma Q, Evanich DJ, Shi Y, et al. High-resolution spatiotemporal transcriptome mapping of tomato fruit development and ripening. Nat Commun. 2018;9(1):364.

3. Kehr J. High resolution spatial analysis of plant systems. Curr Opin Plant Biol. 2001;4(3):197-201.

4. Day RC, Grossniklaus U, Macknight RC. Be more specific! Laser-assisted microdissection of plant cells. Trends Plant Sci. 2005;10(8):397-406.

5. EmmertBuck MR, Bonner RF, Smith PD, Chuaqui RF, Zhuang ZP, Goldstein SR, et al. Laser capture microdissection. Science. 1996:274(5289):998-1001.

6. Obel N, Erben V, Schwarz T, Kuhnel S, Fodor A, Pauly M. Microanalysis of plant cell wall polysaccharides. Mol Plant. 2009;2(5):922-32.

7. Dembinsky D, Woll K, Saleem M, Liu Y, Fu Y, Borsuk LA, et al. Transcriptomic and proteomic analyses of pericycle cells of the maize primary root. Plant Physiol. 2007;145(3):575-88.

8. Schad M, Mungur R, Fiehn O, Kehr J. Metabolic profiling of laser microdissected vascular bundles of Arabidopsis thaliana. Plant Methods. 2005;1(1):2

9. Day RC, McNoe LA, Macknight RC. Transcript analysis of laser microdissected plant cells. Physiol Plant. 2007;129(2):267-82.

10. Gautam V, Singh A, Singh S, Sarkar AK. An efficient LCM-based method for tissue specific expression analysis of genes and miRNAs. Sci Rep. 2016;6:21577.

11. Nelson T, Tausta SL, Gandotra N, Liu T. Laser microdissection of plant tissue: what you see is what you get. Annu Rev Plant Biol. 2006;57:181-201.

12. Gautam $\vee$, Sarkar AK. Laser assisted microdissection, an efficient technique to understand tissue specific gene expression patterns and functional genomics in plants. Mol Biotechnol. 2015;57(4):299-308.

13. Olofsson L, Lundgren A, Brodelius PE. Trichome isolation with and without fixation using laser microdissection and pressure catapulting followed by RNA amplification: expression of genes of terpene metabolism in apical and sub-apical trichome cells of Artemisia annua L. Plant Sci. 2012:183:9-13.

14. Goldsworthy SM, Stockton PS, Trempus CS, Foley JF, Maronpot RR. Effects of fixation on RNA extraction and amplification from laser capture microdissected tissue. Mol Carcinogen. 1999;25(2):86-91.

15. Gotte M, Benard M, Kiefer-Meyer MC, Jaber R, Moore JP, Vicre-Gibouin M, et al. Endoplasmic reticulum body-related gene expression in different root zones of Arabidopsis isolated by laser-assisted microdissection. Plant Genome. 2016. https://doi.org/10.3835/plantgenome2015.08.0076.

16. Yoshida S, Cui S, Ichihashi Y, Shirasu K. The haustorium, a specialized invasive organ in parasitic plants. Annu Rev Plant Biol. 2016;67:643-67.

17. Kokla A, Melnyk CW. Developing a thief: haustoria formation in parasitic plants. Develop Biol. 2018:442(1):53-9.

18. Honaas LA, Wafula EK, Yang Z, Der JP, Wickett NJ, Altman NS, et al. Functional genomics of a generalist parasitic plant: laser microdissection of host-parasite interface reveals host-specific patterns of parasite gene expression. BMC Plant Biol. 2013;13(1):9.

19. Olsen S, Striberny B, Hollmann J, Schwacke R, Popper Z, Krause K. Getting ready for host invasion: elevated expression and action of xyloglucan endotransglucosylases/hydrolases in developing haustoria of the holoparasitic angiosperm Cuscuta. J Exp Bot. 2016;67(3):695-708.

20. Takahashi H, Kamakura H, Sato Y, Shiono K, Abiko T, Tsutsumi N, et al. A method for obtaining high quality RNA from paraffin sections of plant tissues by laser microdissection. J Plant Res. 2010;123(6):807-13.

21. Martin LB, Nicolas P, Matas AJ, Shinozaki Y, Catala C, Rose JK. Laser microdissection of tomato fruit cell and tissue types for transcriptome profiling. Nat Protoc. 2016;11(12):2376-88.
22. Inada N Wildermuth MC. Novel tissue preparation method and cellspecific marker for laser microdissection of Arabidopsis mature leaf. Planta. 2005:221(1):9-16.

23. Kerk NM, Ceserani T, Tausta SL, Sussex IM, Nelson TM. Laser capture microdissection of cells from plant tissues. Plant Physiol. 2003;132(1):27-35.

24. Lenzi L, Caruso C, Bianchedi PL, Pertot I, Perazzolli M. Laser microdissection of grapevine leaves reveals site-specific regulation of transcriptional response to Plasmopara viticola. Plant Cell Physiol. 2016;57(1):69-81.

25. Kozera B, Rapacz M. Reference genes in real-time PCR. J Appl Genet. 2013;54:391-406.

26. Gopalam R, Rupwate SD, Tumaney AW. Selection and validation of appropriate reference genes for quantitative real-time PCR analysis in Salvia hispanica. PLoS ONE. 2017;12(11):e0186978.

27. Wan Q, Chen S, Shan Z, Yang Z, Chen L, Zhang C, et al. Stability evaluation of reference genes for gene expression analysis by RT-qPCR in soybean under different conditions. PLoS ONE. 2017;12(12):e0189405.

28. Li J, Han X, Wang C, Qi W, Zhang W, Tang L, et al. Validation of suitable reference genes for RT-qPCR data in Achyranthes bidentata Blume under different experimental conditions. Front Plant Sci. 2017;8:776

29. Andersen $\mathrm{CL}$, Jensen $\mathrm{J}$, Orntoft TF. Normalization of real-time quantitative reverse transcription-PCR data: a model-based variance estimation approach to identify genes suited for normalization, applied to bladder and colon cancer data sets. Can Res. 2004;64(15):5245-50.

30. Hellemans J, Mortier G, De Paepe A, Speleman F, Vandesompele J. qBase relative quantification framework and software for management and automated analysis of real-time quantitative PCR data. Genome Biol. 2007;8(2):R19.

31. Zhu JK. Abiotic stress signaling and responses in plants. Cell. 2016;167(2):313-24

32. Scranton MA, Fowler JH, Girke T, Walling LL. Microarray analysis of tomato's early and late wound response reveals new regulatory targets for leucine aminopeptidase A. PLoS ONE. 2013:8(10):e77889.

33. Liu MJ, Sugimoto K, Uygun S, Panchy N, Campbell MS, Yandell M, et al. Regulatory divergence in wound-responsive gene expression between domesticated and wild tomato. Plant Cell. 2018;30(7):1445-60.

34. Zegzouti H, Jones B, Marty C, Lelievre JM, Latche A, Pech JC, et al. ER5, a tomato CDNA encoding an ethylene-responsive LEA-like protein: characterization and expression in response to drought, $A B A$ and wounding. Plant Mol Biol. 1997:35(6):847-54.

35. Donaldson L, Williams N. Imaging and spectroscopy of natural fluorophores in pine needles. Plants (Basel). 2018;7(1):10.

36. Verhertbruggen Y, Walker JL, Guillon F, Scheller HV. A comparative study of sample preparation for staining and immunodetection of plant cell walls by light microscopy. Front Plant Sci. 2017;8:1505.

37. Athman A, Tanz SK, Conn VM, Jordans C, Mayo GM, Ng WW, et al. Protocol: a fast and simple in situ PCR method for localising gene expression in plant tissue. Plant Methods. 2014;10:29.

38. Prieto P, Moore G, Shaw P. Fluorescence in situ hybridization on vibratome sections of plant tissues. Nat Protoc. 2007;2(7):1831-8.

39. Blokhina O, Valerio C, Sokolowska K, Zhao L, Karkonen A, Niittyla T, et al. Laser capture microdissection protocol for xylem tissues of woody plants. Front Plant Sci. 2016:7:1965.

40. Rose JKC, Braam J, Fry SC, Nishitani K. The XTH family of enzymes involved in xyloglucan endotransglucosylation and endohydrolysis: current perspectives and a new unifying nomenclature. Plant Cell Physiol. 2002:43(12):1421-35.

41. Olsen S, Krause K. Activity of xyloglucan endotransglucosylases/hydrolases suggests a role during host invasion by the parasitic plant Cuscuta reflexa. PLoS ONE. 2017;12(4):e0176754.

42. Lopez-Curto L, Marquez-Guzman J, Diaz-Pontones DM. Invasion of Coffea arabica (Linn.) by Cuscuta jalapensis (Schlecht): in situ activity of peroxidase. Environ Exp Bot. 2006;56(2):127-35.

43. Svubova R, Lukacova Z, Kastier P, Blehova A. New aspects of doddertobacco interactions during haustorium development. Acta Physiol Plant. 2017;39(3):155.

\section{Publisher's Note}

Springer Nature remains neutral with regard to jurisdictional claims in published maps and institutional affiliations. 